\title{
Cultural Diversity in the Adoption of Open Education in the Mediterranean Basin: Collectivist Values and Power Distance in the Universities of the Middle East ${ }^{1}$
}

\section{La diversidad cultural en la adopción de la educación abierta en las universidades de Oriente Medio: colectivismo y distancia del poder}

\author{
Romina Cachia ${ }^{2}$
}

University of Malta (Malta)

Mohammed Aldaoud ${ }^{3}$

German Jordanian University (Jordania)

Ayman M. Eldeib ${ }^{4}$

Cairo University (Egipto)

Omar Hiari ${ }^{5}$

German Jordanian University (Jordania)

\footnotetext{
${ }^{1}$ This work was supported by the European Commission Erasmus+: Higher Education International Capacity Building Programme, under Grant Agreement Number - 2015-3166/001-001 and Co-funded by the Erasmus+ Programme of the European Union [Project number: 561651-EPP-12015-1-IT-EPPKA2-CBHE-JP] (October 2015-October 2018).

2 (rcachia@gmail.com ) Investigadora de la Universidad de Sevilla, la Universidad de Malta y el JRC de la Comisión Europea. Ha publicado varios informes sobre la creatividad y la innovación en el sistema educativo. Realizó su investigación doctoral sobre las redes personales de los inmigrantes altamente cualificados y los tipos de movilidad geográfica.

3 (mohammad.aldaoud@gju.edu.jo) Profesor de ingeniería eléctrica y tecnologías de la información de la German Jordanian University, Jordania. Ha publicado sobre programación informática, centrando su trabajo en el análisis de imágenes ultrasonido.

ORCID: https://orcid.org/0000-0002-9399-5769.

${ }^{4}$ (eldeib@ieee.org ) Profesor de ingeniería biomédica de la Universidad de El Cairo, Egipto. Ha desarrollado sofware específico para el diagnóstico médico.

${ }^{5}$ (omar.hiari@gju.edu.jo) Profesor de ingeniería eléctrica y tecnologías de la información de la German Jordanian University, Jordania. Ha realizado trabajos de diseño de Hardware.

ORCID: http://orcid.org/0000-0003-3643-8250.
} 


\title{
Adiy Tweissi ${ }^{6}$ \\ Princess Sumaya University for Technology (Jordania)
}

\section{Daniel Villar-Onrubia ${ }^{7}$ \\ Coventry University (Reino Unido)}

\section{Katherine Wimpenny ${ }^{8}$ \\ Coventry University (Reino Unido)}

\author{
Isidro Maya Jariego 9 \\ Universidad de Sevilla (España)
}

Recibido: 23-09-19

Aprobado: 12-06-20

\begin{abstract}
In this paper, we examine how open education is adopted in the Middle East region in the context of a European-funded project for capacity building in Higher Education. Basing our study on Hofstede's model, we examine how culture, in particularly collectivism and power distance influence the adoption of open education. In addition, we look at the relationship between internationalisation of tertiary education and open education. Based on indepth interviews, focus group, and participatory action research with experts

${ }^{6}$ (a.tweissi@psut.edu.jo )Director del Centro de eLearning de la Universidad Princesa Sumaya para la Tecnología, Jordania. Es experto en tecnología educativa y ha realizado trabajos sobre inteligencia artificial y eLearning.

7 (ab8455@coventry.ac.uk) Laboratorio de Medios Disruptivos de la Universidad de Coventry, Reino Unido. Realizó su doctorado en la Universidad de Oxford. Ha publicado trabajos sobre las competencias digitales, las prácticas educativas abiertas, el aprendizaje conectado y la intersección entre tecnologías educativas e internacionalización de la educación superior.

ORCID: https://orcid.org/0000-0001-5908-0701.

${ }^{8}$ (hsx260@coventry.ac.uk) Laboratorio de Medios Disruptivos de la Universidad de Coventry, Reino Unido. En su investigación analiza cómo las instituciones de educación integran aspectos éticos y culturales en el diseño de experiencias educativas, así como el impacto de las mismas en estudiantes culturalmente diversos.

ORCID: https://orcid.org/0000-0002-7338-782X.

9 (isidromj@us.es) Profesor Titular de Psicología Social e Investigador Principal del Laboratorio de Redes Personales y Comunidades de la Universidad de Sevilla, España. Es autor de "Estrategias de Intervención Psicosocial" y "Comunidades preparadas para la salud". Fue investigador principal del proyecto Erasmus+ de la Unión Europea "OpenMed” en la Universidad de Sevilla. Ha participado en proyectos del plan estatal de I+D+i (España), de COLCIENCIAS (Colombia), FONDECYT (Chile) y CONACYT (México), entre otros.

ORCID: https://orcid.org/0000-0002-2568-5048* Corresponding author.
\end{abstract}


in the fields from Egypt, Jordan, Lebanon and Palestine, our findings suggest that beyond the technical aspect and the development of content, adoption of open education in the Middle East region is influenced by cultural aspects, which needs to be taken into consideration. As an emerging sub-culture, open education has the potential to transform and change some cultural barriers related to both power distance and collectivist cultures.

Key-words: Open Education, Middle East, Individualism-Collectivism, Power Distance, Community Readiness.

\section{Resumen}

En este artículo mostramos cómo la adopción de recursos educativos abiertos en las universidades de Oriente Medio depende en parte de factores culturales, tales como el grado de individualismo/colectivismo y la distancia a la autoridad. Utilizando el modelo de Hofstede, describimos el caso de un proyecto Erasmus + para el desarrollo de capacidades en Educación Superior en el que se promovieron prácticas abiertas en instituciones de educación superior en Egipto, Jordania, Líbano y Palestina. Los resultados muestran cómo el grado de internacionalización es un antecedente directo de la incorporación de prácticas educativas abiertas en el contexto universitario.

Palabras-clave: Educación abierta, Oriente Medio, individualismo/ colectivismo, distancia del poder, preparación comunitaria.

\section{Introduction}

The past decade has marked a period of massive transition in higher education. On one hand, students used to a technological environment where access to information is free and instantaneous, have created demand for more innovative higher education pedagogies. On the other hand, policies on education have prioritized accessibility of quality higher education. Open education is argued to be one of the enablers that could lead towards improving higher education, providing a space for collaborative learning and knowledge co-creation among learners from different cultural backgrounds (Gervedink Nijhuis, Pieters, \& Vogt, 2013).

Open education is somehow related with distance learning, flexible learning, the widening of access to education; and the promotion of selfdirected learning, to mention a few (Bulger, Bright, \& Cobo, 2015; CastañoMuñoz, Kreijns, Kalz, \& Punie, 2017; Castaño Muñoz, Redecker, Vuorikari, \& Punie, 2013; UNESCO, 2012). Similar to other asynchronous and distance 
applications, open education is argued to be a bridge to temporal and spatial obstacles (Leeds, 2014). Notwithstanding, while distance learning is a set of tools that provide ability for learning at the student's own time and space, open education offer opportunities to education using distance or face-to-face learning. However there is limited evidence of how open education resources (OER) are localized and integrated into actual teaching and learning practices in different cultural contexts (Butcher \& Hoosen, 2014).

Educational resources are always produced in specific socio-cultural contexts, which establishes certain limits and opportunities from the outset for their reuse. Historically, United States has always been the front-runner in producing and consuming software. The global reach of some of these products raised the awareness that certain features had to be adaptable to different locations. For instance, in France, in order to reach the local market, language was indispensable for the use of software (Marcus, 2000). Similarly, the widespread diffusion of OER, like other Western-oriented instructional materials, requires careful examination and understanding of the applicability and limitations of these materials in different cultural settings (Zualkernan, Allert, \& Qadah, 2006).

This paper reports on a qualitative interpretation of how socio-cultural barriers may influence and shape how open education is adopted in the Middle East. The Middle East is an interesting context because apart from the limited studies focused on open education (Affouneh, Wimpenny, Ra'fat Ghodieh, Alsaud, \& Obaid, 2018), its socio-cultural context differs substantially to the origin of open education. The scope of this work is higher education across four countries in the South Mediterranean, namely Egypt, Jordan, Lebanon, and Palestine, as part of a European funded project called OpenMed. ${ }^{10}$

\section{Cultural aspects for open education}

Open education relies on two fundamental ideas: (i) free and open access to knowledge; and (ii) adapting and re-using existent pieces of knowledge which are in the public domain or have been released under an intellectual property license which allows free reuse or adaptation by others (Abeywardena, 2012). However, for open education to be truly widespread and useful to diverse learners and communities, the evaluation of the transferability of OER from one context to another is required, taking into consideration the pedagogical methods and approaches to teaching and learning adopted (Hatakka, 2009).

${ }^{10}$ The OpenMed project is a three-year project $(2015$ - 2018) funded by the European Union aimed at raising awareness and facilitating the adoption of Open Educational Resources (OER) in the Arab Mediterranean countries, with main focus on higher education in Egypt, Jordan, Morocco and Palestine.

Araucaria. Revista Iberoamericana de Filosofia, Política, Humanidades y Relaciones Internacionales, año $22, \mathrm{n}^{\circ} 44$. Segundo semestre de 2020. Pp. 53-82. ISSN 1575-6823 e-ISSN 2340-2199 https://dx.doi.org/10.12795/araucaria.2020.i44.03 
To examine these cultural dynamics in open education, Hofstede's (1980) multi-dimensional model of cultures has been used as a theoretical framework. Basing his analysis on an International Business Machines (IBM) employee database, Hofstede identified four polar dimensions to describe cultural differences, namely: individualism/collectivism, power distance, masculinity/ femininity and uncertainty avoidance. A fifth dimension, long/short-term orientation and a sixth, indulgence were later added based on research carried out in Hong Kong and China (G. Hofstede \& Bond; Minkov \& Hofstede, 2012). While Hofstede's model has received considerable criticism (Jones, 2007; Nasif, Al-Daeaj, Ebrahimi, \& Thibodeaux, 1991; Signorini, Wiesemes, \& Murphy, 2009), various researchers concur that his model remains valid, and useful for studying some aspects of intercultural settings (Søndergaard, 1994), especially at macro-culture level.

Based on previous research (Maya Jariego \& Santolaya, 2016; Thomas, 2008), whereby it was verified that individualism-collectivism and power distance dimensions established significant differences in the Middle East region, we have opted to focus this article on these of two dimensions, given they are of most relevance for open education.

\subsection{Individualism/Collectivism}

The first dimension, individualism/collectivism refers to differences in culture in terms of whether individuals are more likely to safeguard their own individual needs and interest over their own community. When examining education, Hofstede (2011) found significant differences in the way education was perceived by different cultures. Societies that are more collectivist in nature base their educational approach on reputation, and the imperative of gaining prestige in one's society and ensuring that formal harmony is maintained. Students are expected to learn how 'to do', as opposed to how 'to learn', will only speak in class when spoken to by the teacher and adults cannot adopt student roles. Through such teacher-centred approach, the students expect the teacher to lead them through the learning objectives, given the teacher is viewed as having all the answers and being responsible for 'transferring' the knowledge to them.

On the other hand, societies that are more individualistic tend to prioritize their education models around lifelong learning, and improving one's selfrespect based on ability and competence, whereby the latter is more important than accreditation. Students are expected to speak up in class, and are encouraged to be independent from an early age. Confrontation and debate are perceived as a means to understanding of a topic, rather as direct criticism. 
Various studies have demonstrated that differences in learning styles are often attributed to cultural factors relating to individualism/collectivism (Auyeung \& Sands, 1996; Sugahara \& Boland, 2010). For example, when compared to Australian students, Chinese students were more likely to be engaged in collaborative approaches in researching and writing assignments (Tang, 1993). A preference for more abstract and reflective modes was also found in accounting students from Taiwan and Hong Kong, when compared to Australian students, who preferred active and concrete modes, which the authors also attribute to individual/collective values in the cultures studied (Auyeung \& Sands, 1996). In a further study, Ramburuth \& McCormick (2001) found that Asian international students were more likely to prefer group learning, when compared to Australian students.

In the context of open education, highly regarded values in collectivist societies may interfere with the adoption of open education. This does not mean that open education is not possible in collectivist cultures, but rather to suggest that there is some cultural discordance necessary to take into consideration. After all, open education is a concept developed within an individualistic society. The learning process, within an open education culture is based on self-directed learning, whereby the learner proactively choses the content, the method, and at times, even the method of assessment. An orientation towards self-direction signifies a person's own capacity for individual action, as opposed to the collective (Lenartowics \& Roth, 2001). Accordingly, students learning within an individualistic culture are more likely to be expected and encouraged to be active in their learning and hence, tend to feel more comfortable in unstructured learning situations. These aspects were already highlighted in previous studies on distance learning.

In reviewing literature on distance learning, Al-Harthi (2005) examined how different studies have shown that distance education tends to fit better in an individualistic cultural-oriented society, mainly because distance learning is often associated with self-directed learning. In a survey to students from two US universities, Anakwe, Kessler, \& Christensen (1999) found that individualists and collectivists differ in their perception of distance learning. While a student's cultural orientation within an individualist culture is based on self-interest (independence, self-reliance and competitiveness), a student's attitude within a collectivist culture is shaped more by collective interests (interdependence and cooperativeness). Further, studying how students from Asia and Europe cope with isolation in distance learning through a Master's degree, Venter (2003) found that student's cultural background had an influence in the way they experienced isolation in distance learning. The differences were mainly attributed to different perceptions about the way students viewed the teacher-student relationship. Asian students' isolation was mainly related to the 
lack of the authority figure of the teacher, "the person with "the answers" (p. 277), to help understand and clarify the points. However, for their European counterparts, it was the lack of opportunity for discussion and debate, which they perceived beneficial for learning.

\subsection{Power Distance}

The second dimension referred to as power distance represents how people in different cultures have different degrees of tolerance towards inequality in power. Hofstede (1986) explores how the parent-child relationship in one culture is often extended to the teacher-student relationship in education. If the parent-child relationship is based on obedience, this is often reflected in the teacher-student relation. Teachers are admired for their brilliance as opposed to their friendliness and students chose their subjects according to career opportunities, instead of intrinsic interest.

In this aspect, it is not difficult to see that OER developed for a culture with low power distance may not be entirely apt for a culture with high power distance without some modification that takes into account the cultural differences. Power distance does not relate merely to the relationship between teacher and student, but also to other underlying aspects, such as whether the teachers are free to define their own curriculum (Archers, 1979), whether instruction is teacher led, or how the teaching position is perceived within each culture, among other aspects. Moreover, research has shown that students from different cultures have different cognitive ability profiles (Schkade, Romani, \& Uzawa, 1978; Schribner \& Cole, 1981), which may demand different didactic approaches. Culturally different students tend to process and retain new and different academic information distinctly (Dunn, 1983).

In a study with students learning web interface design, Marcus (2000) found that the power distance present in a culture could also be detected in the design of the websites by the students. Students from high power distance countries were more likely to design websites with high level of structured information, more access control and security restrictions.

In the context of OER, for instance, a MOOC designed by an American professor who is accustomed to student-led learning, might provide less specific instruction taking into account that students will do the research on their own. However, in a context where students are not used to working on their own, and are usually requested to follow the professors' instructions, they might feel slightly lost in the absence of directive teaching. Some students might feel disoriented when the orderly and formal setting of the classroom is taken out of the learning process, as was found by Knox (2014) in the study on MOOC users, who claimed to feel overwhelmed with the large volume of 
activity in such massive environments. The exception to the rule seems to be in technology-based subjects that have a long tradition of being elaborated and highly based on western resources, such as computer science and computer engineering (Zualkernan et al., 2006).

With few exceptions, most literature addressing cross-cultural dimensions are based on studying the Asian-Western dichotomy. We have come across few studies (Al-Harthi, 2005; Zualkernan et al., 2006) that take the middle-east cohort when studying any of these cultural factors. Moreover, there are hardly any studies examining how cultural factors could influence open education (Maya Jariego, 2017).

\subsection{Internationalisation through open education}

A major discussion in expanding open education, especially in regions where mobility may be limited, is online internationalisation. For universities, networking learning provides a variety of possibilities, ranging from lowering educational costs and widening universal access, to expanding international experiences providing diverse opportunities for intercultural interaction for a wide variety of students (Villar-Onrubia \& Rajpal, 2016). Internationalisation of tertiary education is widely believed to be a positive advancement and over the past three decades, it has become an axiomatic concept of good quality (Yemini \& Sagie, 2016). Graduates are expected to be able to speak foreign languages and develop intercultural skills to be able to interact in the global setting. In terms of outward mobility, the number of students studying abroad has doubled from 2000 to 2010 (OECD, 2012).

Nevertheless, student mobility is only one aspect of internationalisation. Open education could be another opportunity for internationalizing tertiary education, given it provides a variety of platforms through which diverse students and staff come together and where teaching and learning can be carried in an international context. Arguably, this could fit very well with Internationalisation at Home initiatives aimed to achieve internationalized learning outcomes without the need for mobility. However, the appropriation and dissemination of open education may remain futile, if professors are not guided in developing appropriate competencies to effectively manage cultural diversity (Maya Jariego, 2017).

A major question that emerges out of this development is, to what extent are "international" resources easily adapted to different cultural contexts? Although over recent years, there has been an increase in OER created in different countries, the major suppliers of OER are still based in the West. Similarly, various instructional material and techniques used in technology education is of Western origin and are often used in non-Western settings 
(Zualkernan et al., 2006). The availability of OER in languages other than English is another issue explored by Richter and McPherson (2012). In some regions, translation of resources is necessary, and even then, adaptation is still needed. Beyond language, adapting OER to the cultural context can vary from taking into consideration political conflicts, taboos, potential sexual connotation and hierarchy, to mention but a few.

While the exchange of education resources could provide platforms of intercultural communication and could be a valuable vehicle for contributing towards the education of competent graduates, unless the teaching and learning materials developed are able to be adapted to different cultural contexts, they will have limited use. Moreover, it is important to consider whether the sharing of contextually biased OER will actually be transferable within fundamentally different contexts (Richter \& McPherson, 2012). In this respect, open education could be viewed as a gateway for internationalisation, or an obstacle to it. A higher education institution with an international profile has a higher readiness for open education and is, thus, more likely to adopt open education policies (Maya Jariego, 2017).

\section{This study}

The study aimed at identifying cultural barriers that might hinder the transition to open education in higher education in the Middle East, specifically in Egypt, Jordan, Lebanon and Palestine. In order to understand better how culture may jeopardize the transition to open education, in-depth interviews were conducted with experts in the field who could contribute with local and cross-cultural knowledge.

Specifically, we try to explore how the cultural distance between the Arab and European countries of the Mediterranean affects the adoption of open educational resources. To this end, we examine the influence of collectivist values and high-power distance in higher education institutions in the Middle East when incorporating open educational practices within the framework of a European Erasmus + project. In addition, we try to see how this process is modulated according to the degree of internationalization of each university.

\section{Participatory action research design}

In this study, we applied participatory action research (PAR) design combining, (a) participant observation in the project partner meetings with (b) in-depth interviews and (c) a focus group with the facilitators. The facilitators, 
apart from acting as partners in the OpenMed project, were also in charge of managing a local circle of learners, who participated in a course on open education designed by the OpenMed partners.

At the time of the interview, the experts played an active role in open education in their institutions and were all participating in a European funded project called OpenMed. ${ }^{11}$ The project was aimed at promoting open educational practices in the South Mediterranean region and lasted between 2015 and 2018. Within this project, the experts were both partners in the project and facilitators in their universities managing different Local Learning Circles within their own universities. The local circles were designed to enhance and disseminate open education knowledge and practices with university staff.

The partner meetings allowed for visits to the participating universities in Egypt, Jordan, Morocco and Palestine. The meetings were organized periodically throughout the three years period of the project. This allowed us to know the educational contexts in situ and the projects carried out. It also served us to reflect, in a participatory manner, on the opportunities, barriers and results of open education in the region.

The interviews were conducted with 7 of the facilitators, who participated voluntarily. Two facilitators from Egypt, 2 from Jordan, 1 from Lebanon and 2 from Palestine were interviewed, representing 7 different universities ${ }^{12}$. In the interviews, open questions were asked about the opportunities and barriers for open education in the region, the competences of the facilitators, the management of local circles and the cultural adaptation of open educational practices. The interviews lasted around 45 minutes on average and were transcribed literally.

The focus group was held in one of the lasts partners' meeting with the aim to serving to validate the information previously obtained in the interviews. Some of the provisional conclusions obtained from the interviews were presented to participants. Two facilitators from Egypt, 3 from Jordan, 2 from Morocco and 1 from Palestine participated in the focus group. The topics suggested in the discussion were the experience of collaboration in groups of teachers in each local circle, the role of the academic hierarchy in the adoption of open educational practices, and the use of Arabic or English in the didactic materials, among others. The literal transcriptions of both the interviews and the discussion group are available with a Creative Commons 4.0 license in Zenodo (Cachia \& Maya-Jariego, 2018).

11 The expert from Lebanon was the only one who was not a formal partner of the OpenMed project, even though he was collaborating in the project. Although the project was covering the MENA region, in this article we decided to focus in the Middle East in order to obtain more consistency in the observations.

12 We interviewed seven open education experts, from seven universities in four countries: Alexandria University (Egypt), Cairo University (Egypt), German Jordanian University (Jordan), Princess Sumaya University of Technology (Jordan), Notre Dame University (Lebanon), Birzeit University (Palestine) and Al-Najah University (Palestine). The experts included professors across different ranks in a variety of disciplines. 


\subsection{Participatory approach and procedures}

The PAR procedure consisted of an iterative process of interpretationconfirmation that served to contrast the validity of the conclusions. The interpretation from partner meetings were contrasted in the interviews and the focus group. The participants reviewed the transcripts of the interviews and the focus group. They also reviewed the conclusions report with the interpretation of results.

The participatory action research process was divided into 6 consecutive steps. First, the meetings of partners throughout the project served to observe the barriers and facilitators that the university system faced in each country. Second, the national strategic forums provided a basic knowledge of the key actors and the most significant experiences of open education in each context. Third, based on this background, a small group of European partners designed the interview format, with open questions and a structured thematic script. Fourth, individual interviews with experts were carried out and a systematic analysis of the contents was applied. Fifth, the preliminary results were presented and discussed at a partners' meeting and validated in a focus group with 8 participants from the region. Finally, the qualitative analysis was shared with four of the seven experts interviewed, who made contributions and participated in a consensus-evaluation exchange. Thanks to this iterative process, the analysis is based on the shared reflection of the participants in the project.

The in-depth interviews were carried out using Skype and took place between February and March 2018. During the interviews, the experts were asked about the management of the local circles, the cultural adaptation of the university and the role of the facilitator. Open-ended questions were used so as to allow the interviewees to answer from their own frame of references. The interviews lasted around 40 minutes and were conducted in English. The data collected during the interviews was recorded and later transcribed and sent to the interviewees, so as to ensure that the interviewer was making an accurate interpretation of what was said during the interview.

This participatory approach has been used previously in the region and has proved effective in providing context-based solutions to educational problems in Egypt (Abdallah, 2017)) or Palestine (Al-Qura'n et al., 2001). Implementing culturally-appropriate research is essential in educational settings, specifically in choosing methods, conducting best communication during assessment with proper transcribed material that suits the culture and perception, identifying and describing participants, and culturally appropriate analysis of information and data (Ember \& Ember, 2009). Furthermore, people from different cultures think differently (Heine, 2011), and this is a fact that articulates the need of 
well-organised methodology to fit with cultural differences. Echoing previous studies, our aim was to "give human voices to Hofstede's numbers" (Signorini et al., 2009, p. 598).

\subsection{Data analysis}

The interviews and focus groups were analysed following a shared thematic analysis approach. An iterative process of coding was carried out, comparing similarities and differences between universities and between countries, so that the thematic categories were gradually emerging (Corbin \& Strauss, 1990). The analysis involved two team members, who discussed the resulting thematic analysis and reached consensus in case of divergence. Two reports on the qualitative material were written in parallel, which served as a contrast element of the interpretations made by both observers.

The consistency of the findings was improved through the focus group after the interviews, which served to confirm some of the interpretations made during the first phase of the analysis. The transcripts were also presented to the informants before proceeding to their analysis. Objectivity of data collection and analysis was based on the formulation of open and neutral questions, as well as on the presentation of the transcriptions to the project consortium, so that the information could be revised, corrected and extended.

\section{Results}

The OER movement is based on free access to knowledge and re-use and adaptation of available resources. In this context, we have asked the participant experts in the region, how OER is being adapted in their countries and institutions. While each country is unique in the way it adopts open education, beyond the obvious barriers of access and institutional politics, there are other cultural barriers that are more homogenous across Middle Eastern universities. In this section, the cultural barriers as identified by our experts are shared.

Informants pointed to time constraints and reluctant attitudes towards innovation as the main barriers in the adoption of open educational resources. The academic hierarchy is also viewed as playing a central role in the process of organisational change, which interestingly can also be the lever that facilitates the innovation process. On the other hand, the language and degree of internationalisation of the curriculum (IoC) at the partner universities are particularly significant motivating factors. Although collectivism and power distance are transversal factors, according to the analysis of key informants, they are reflected especially in the functioning of the organisational structure. 
We have summarized the factors identified by the experts in Table 1. The results of this study are presented along six aspects related to how culture may influence the adoption of open education in the Middle East, namely: reluctance, reputation, language, internationalisation, time and sustainability.

\subsection{Reluctance}

Understanding the teacher/student relationship was viewed as fundamental when discussing cross-cultural learning. Hofstede (2001) argues that such interaction is deeply rooted in the culture of a society. Within the context of open education, the difference in the social position of teachers and students may cause some cultural barriers, in terms of different understandings of what is expected from each role. Consequently, some implicit aspects need to be taken into account when discussing opening education in the Middle East region.

A major concern highlighted by various experts is the reluctance of professors and students in embracing open education. There is still a lot of scepticism on the benefits of open education. For many people in tertiary education, it remains a challenge to think of education outside the formal institution, where you attend a course physically and get your diploma/degree certificate at the end.

"Specifically, for Jordan, there is a cultural challenge. Not only [do] teachers think that online/open courses are not good enough to deliver knowledge, but also the students think that." (Expert 5, Jordan)

Open education may also be perceived as a threat by some professors, as it defeats a defined successful model of teaching which has been developed and practiced over many years. There are still a significant number of professors who lack basic ICT skills and hence, bringing them to open education is a major challenge:

"I think for older professions to be involved, it is more difficult than younger.

The younger professors have already ICT knowledge and skills. An older professor might not have the skills in ICT. This would be a barrier to come to open education." (Expert 4, Egypt) 
Table I. Institutional barriers and cultural peculiarities in the adaptation of open educational resources in the universities of the Middle East

\begin{tabular}{ll}
\hline \multicolumn{1}{c}{ Factors } & \multicolumn{1}{c}{ Description } \\
\hline Reluctance to open \\
education
\end{tabular}$\quad \begin{aligned} & \text { Education is conceived as a process that takes place in formal } \\
& \text { contexts, which may be threatened by innovations through } \\
& \text { open practices. } \\
& \text { Teachers and / or students sometimes perceive a lack of in- } \\
& \text { formation and communication skills required to implement } \\
& \text { open educational practices. } \\
& \text { Educational innovations have to be embodied in university } \\
& \text { policies and therefore not only depend on the attitudes of } \\
& \text { teachers, but the institutional context. }\end{aligned}$


Various professors do not yet understand why they should open their teaching and learning and the potential benefits of open education. Professors active in open education still see their efforts as individual initiatives and not as a movement that is part of the university organisation. The need to formalize and license the publication of OER material by teachers was discussed as an important step to take in the near future, together with the development of strong platforms to host OER material and the need for a change in policy at an institutional level. As one expert explained:

"I would like to have it $100 \%$ open, but we have some limitations with the policy and the regulation of exams. I cannot make an online evaluation. It has to be on campus and paper exams until now." (Expert 4, Egypt)

The need for a change in policy related to OER was highlighted by most experts. In most countries, only a small percentage of a university course could be conducted through open practices and the policy is not clear on how professors should use OER in the classroom. Without a change in policy, efforts in adopting open education will remain silo efforts:

\begin{abstract}
"First of all, you have to go through stages when you introduce open education to an institution. The most basic step is training and awareness. Anyone trying to champion OER or introducing OER in his/her institution, they have to have passion about OER. They have to understand and locate champions in the institution...if they believe in the benefits in OER for both themselves and for the students, then they will follow you. This is what I am trying to do at the university. This is why now I have so many champions working with me in this area." (Expert 3, Jordan)
\end{abstract}

Access to OER means various resources are at the students' disposal. This presents a major conflict with professors who primarily rely on traditional models of instruction, whereby the professor is the one and only supply of knowledge. In some cases, high-ranking professors may perceive open education as an assault on their reputation, which may put in question their privileged position and losing control of one's own material:

\footnotetext{
"Still we have a sector of seniors who still have barriers in sharing their material online because of financial causes. They seal their material. If it is available online, it will be a financial disaster for them. Perhaps, because they do not have enough ICT skills and cannot develop their MOOCs. This is a challenge to change the cultural background to open the hard box (hard drive) to open education resources" (Expert 1, Egypt)
}

Teacher-led learning tends to be positively related to less independent students, who would rather have the professor outline their learning paths. In 
such cases, efforts in integrating open education at a wider scale within the university are very challenging. It is not just a matter of providing ICT training or that some professors might not perceive open education as beneficial, it relates to a deeply ingrained culture and requires a profound shift in mindsets and attitudes, not just practice. Within an open education environment, the development of self-directed and active learning is highly encouraged and while the professor is expected to guide the student, it is the student who decides how $\mathrm{s} /$ he wants to learn. Learners have the flexibility to choose from a variety of learning resources that are suited for the development of their expertise. The central benefit of distant, open learning is that it put the process of learning at student's own pace in terms of time and space.

The explanation provided by one expert identifies the problem. While everyone seemed enthusiastic about eLearning, on the contrary there is high reluctance for open learning. His explanation for such difference lies in one being a contribution to the development of individual skills and the other one being a culture in itself. Changing a culture is a challenging process, especially because there are many stakes in question.

\subsection{Reputation}

When discussing the management of the local cohorts of participants called the Local Learning Circles - in the OpenMed capacity building course with the facilitators, the ranking of professors was repeatedly discussed. Facilitators, being themselves also professors, highlighted the importance of paying attention on how to address and communicate with higher-ranking professors. For each local circle, the facilitators had the challenging role of bringing together learners that included professors to acquire open education skills and knowledge. These local circles ended up bringing together professors from different ranks, where experts felt that communication skills and maintaining harmony were indispensable for an easy transition to open education.

\footnotetext{
"Communication skills need to be really high in our country. Some professors if you talk to them, they would not be cooperative. How to communicate with them is a key. The communication of how to address them, to get them involved in open education activities is one thing we need to think about." (Expert 4, Egypt)
}

In some countries, facilitators even perceived themselves as playing an important role in mediating between different academic ranks and thus, bringing together, a group of open education across different roles and rankings. 
"For example, for a Vice Dean of a Faculty to be in the same table with the Assistant Lecturer was not an easy task. But it ends up by being a success, because we enjoy it." (Expert 2, Palestine)

Bringing together different professors from different ranks, so as to keep the group "harmonized", was described by our experts as a challenge, but which was eventually perceived as success. Speaking about the different rankings in her Local Learning Circle, one of the experts explained:

"We are different categories. Even though we are all enthusiastic about the (open education) course, to keep all of them harmonized was a challenge. And also, because we have different backgrounds and different interests. The harmony of the group, which was very nice, [and] ended up being a success, rather than a challenge.” (Expert 1, Egypt)

Another common cultural barrier discussed is the adult in his role as a learner. In his study on education, Hofstede found cultural discrepancy in the way adults as learners are perceived. Education institutions rooted in collectivist culture are less likely to honour adult learners, which in many ways is opposed to the idea of widening access to learning and lifelong learning often underpinning open education approaches. In this respect, one participant explained that everyone in the Local Learning Circle was learning, whether students or professor, and as such everyone should be treated as a partner:

"I cannot treat them as students and that is one of the cultural things that I have to highlight. Some of them are technicians, doctors and professors, and even a higher rank than me. I treat them as partners. I am learning as well and I am here to help them." (Expert 5, Jordan)

Another facilitator commented that as a project with a strong emphasis on bottom-up strategies, the facilitator should be capable of convincing and attracting other professors to open education by showing them the benefits of being involved by being a role model rather than forcing them to participate. This issue was brought up by another expert when discussing the issue of time: it was explained that as a facilitator one has to be very cautious in not exerting too much pressure on the learners. The majority of professors embracing open education are still doing this on a purely voluntary basis and in almost all cases the professors were not allocated specific professional time from their other duties to engage with and facilitate their OER work. As one expert argued:

"They are trying their best along with all the teaching tasks and their private time with their families, etc." (Expert 2, Palestine) 


\title{
5.3. Language
}

During the interviews, the issue of language was often discussed. Teaching in English was perceived as a bridge towards an easy transition to open education. In the Middle East region, English seems to be widely used in international universities.

\begin{abstract}
"At my university, we use the English language it is not same as Egypt or in Palestine, where Arabic is the main language of teaching. There [at my university] people will have much harder time to find the resources, localize and translate to the Arabic language. Also, the cultural issues are very important. They have to be careful with materials they bring because of cultural issues. We do not have these issues at my university, because it is a Lebanese University adopting the American system". (Expert3, Jordan)
\end{abstract}

The use of English in the science departments was also highlighted by various experts.

\begin{abstract}
"In the Faculty of Medicine, it is totally in English. In science and engineering, they have special programs which are in English. Others are in Arabic, in all sectors of humanities, except for those studying foreign language." (Expert1, Egypt)
\end{abstract}

Experts also reiterated the lack of OER in Arabic and the increasing need for such material. For instance, in Palestine there seems to be a higher need to produce OER in Arabic. Our Palestinian experts explained various initiatives that have taken place recently in order to produce and disseminate OER in Arabic. For instance, experts discussed how over the past months, social issues, such as bulimia and digital safety, were addressed through open courses developed in Arabic. While there are plenty of OER in English about these issues, there are hardly any resources in Arabic and hence, they felt the need to create such OER.

Trust is another aspect that came up in the interviews relative to language. According to our experts, students seem to trust the content of an article if it is written in English, more than if it was written in Arabic. This cultural perception that Arabic content is inferior seems to be related to the discrepancy in the amount of content available in English and Arabic. Experts discussed how the rapid increase in content in Arabic could change this cultural perception. Nonetheless, at present this poses a dilemma, which our experts often face: on the one hand, the need to develop more OER in Arabic, specifically tailored for one's own cultural setting within a community (hence, developing tailored resources for one's community) and on the other hand, developing OER in English, so as to reach to a wider more international audience. 
Hence, while teaching in English is one of the factors contributing towards a higher readiness in some universities for adopting open education and also as an international marker, translating the material to Arabic was considered by other universities as an opportunity to become pioneers in creating and adapting OER in Arabic. In this aspect, we have observed that the adaptation of OER is carried out slightly differently, not only per country, but also depending on the faculty and whether instruction is already done in English or not.

\subsection{Internationalisation}

During the interviews, a homogeneous perception of cultural proximity towards the West was observed. Findings from the interviews may be categorized in the dual role of open education as explored by Maya Jariego (2017) where internationalisation is seen simultaneously as a pre-set for open education and as a conduit for the adoption of open education.

Open education seems to be more easily developed in universities where some kind of internationalisation is already in place. During the interviews various aspects were identified which referred to such internationalisation. Most of the experts interviewed have studied and worked abroad, mostly in United States and Europe. Some of them collaborate academically with researchers in the West and in some cases, the university model seeks to replicate Western universities. Some of the universities offer various opportunities for their $\mathrm{PhD}$ students to finish their degree abroad and most outgoing students prefer Europe or study opportunities in the United States. The comparison with the West is a concurrent issue, especially in the context of open education.

In terms of cultural adaptation, experts in Jordan explained that the adaptation of OER is quite straightforward. There is less need for cultural adaptation, mainly because Jordanians feel close culturally to Europe and hence, they feel that any international course would work, especially when comparing themselves to more traditional countries such as Saudi Arabia. One of the experts explained how when asked to redesign a course for a Saudi Arabia audience, the material had to be culturally adapted, for instance, by the removal of women from all the images and videos.

"We started to readapt the course by removing any female picture or video because they didn't want that in Saudi Arabia. That course was provided for male students. Until today, there is still a high-level of segregation between male and female." (Expert 5, Jordan)

Also, in Lebanon, the cultural adaptation of the material for the cultural context was identified as an important aspect. The resources used: 
"...may be based in an American context. The faculty member may have to be careful when using it because it might cause some tension. It depends on the course and the material. If they want to use a picture or a video, they have to be careful with the cultural issues." (Expert 6, Lebanon)

In Palestine, open education is also perceived as an opportunity for internationalizing tertiary education and which could act as a bridge to the outside world. Experts discussed open education as a way of facing political challenges related to movement restrictions across borders. Referring to students in the West Bank and Gaza, one of our experts describes how:

"These students have never been outside Gaza, [nor] outside that one square kilometre area. For them giving this international exposure through OER, is an added value, it is an eye and mind opener, it gives them a sneak peak of what is happening in the international world. It (open education) is major need for Palestine, out of all the countries in the world, because I think there is no other country in the world who have restrictions on movement as we do in Palestine." (Expert 2, Palestine)

In terms of students, experts in Egypt and Lebanon discussed how students were interested and motivated to have OER, as well as happy to have different types of resources, beyond the text book. As the experts explained:

\footnotetext{
"This is encouraging for them (students) to participate. They are learning something and to see how their skills level out internationally. These courses give them an idea on how to measure their skills on an international level and not just on a local base." (Expert 4, Egypt)

"In brief, we had very positive response from our students and they were happy with the materials, and with the different type of resources, not just the text book." (Expert 6, Lebanon)
}

All our experts agreed that international collaboration is key and beneficial for their universities. Cross-boundary collaborative efforts around open education may be another opportunity for internationalizing tertiary education as a way of connecting to the world, of sharing resources with other fellow colleagues in different universities, and in creating an extensive environment for collaboration. Open education provides a variety of platforms through which diverse students and staff come together and where teaching and learning can be carried in an international context.

\subsection{Time}

All the experts interviewed highlighted time as the major barrier for embracing open education. While time could be an important cultural barrier, 
in this context, the issue of time was considered in a more generalized manner, possibly reflecting a worldwide academic challenge. Experts described how most of the professors in their learning circle were not only working in open education voluntarily, but also most of them are doing the work in their leisure time. As one of the experts told us, when he looked at the logfile, he could see how the learners would sign up, try to do as much as they could, and then get back to the work when they finish working:

"The most productive period was before beginning of the Fall semester and at the end of it. We are talking about this small vacation period between two semesters, which is about ten days. Whenever there is a vacation or a break from teaching, they had time to go back to their laptop and work". (Expert 5, Jordan)

In comparison to faculty members using already developed resources, professors using OER spend huge amount of time trying to find quality resources, mapping the different resources, evaluating and adapting the resources to one's curriculum.

"This is very time consuming. You have to have passion. You have to believe why you are doing this and how important it is for your students and to yourself as a professor". (Expert 6, Lebanon)

Most experts highlighted that a better transition to an open education environment is possible if professors are released from some of their duties and given time specifically dedicated to open education.

\subsection{Sustainability}

The long-term benefits of open education were very present in the general discourse of the experts. Replacing text books with OER could result in the cutting of costs not just for the university, but also for the students. The permanence and efficiency of resources was also discussed. Sometimes, students have to wait for several days for their text books because of shipping delays and end up buying older editions, which can be futile for their course:

"With OER, your material is updated, you can update on the go wherever you are teaching." (Expert 6, Lebanon)

In some countries, the decline in book purchases has prompted book publishers to offer online resources, so as to compete with OER. However, such resources tend to be against a fee and also for use during a limited time. On the other hand, OER is available at the students' disposal during the entire 
degree and beyond. As one of the experts said, the availability to academic information at one's own disposal for long periods of time is one of the open education benefits discussed:

"Availability of OER is very efficient. For instance, a virtual hospital, a virtual world, a video about a part of the cadaver. It is important to have the material online and available all the time". (Expert 1, Egypt)

Another issue highlighted by one of our experts is sustainability of open education resources. In some universities, while professors were encouraged and, in some cases even given a grant to create a MOOC or transfer to OER, there is less effort and thought dedicated on how to sustain such efforts. As one expert explained, a major concern is how to maintain the course after it finishes:

"How to update and modify. If I have a course already created in the OER concept, after one year, definitely I need to update the evaluation. Creating a course is not the end of the process, it should be a continuous process." (Expert 4, Egypt)

Sustainable efforts can only be achieved when appropriate policy changes have taken place. The experts we have interviewed clearly understand the benefits of open education, and in fact, a couple of them even mentioned various bottom-up approaches taking place in their universities, as efforts to embrace open education. One of the experts explained how he promotes OER by teaching it, thus shifting the focus on the students. Another expert explained how in his university, a student organisation called the Creative Commons Society has been set up by students to help tell other students about open education, OER and the use of Creative Common licenses. Such efforts clearly illustrate that while individual initiatives are present, there is still a gap between what is currently being done and what the experts would like to see in the near future.

\section{Discussion}

The main findings of this work are related to how the adoption of open education in the Middle East region is influenced by cultural aspects. This is consistent with previous studies, which have highlighted the important dimension of culture when considering technology-uptake (Anakwe et al., 1999; Nelson \& Clark, 1994). The importance of local characteristics in educational innovation has also been proven in the implementation of European projects in Eastern Europe (Fazekas, 2018, Halász, 2018). 
The inception of open education is associated with the development of a Western sub-culture, which in recent years has been given significant political priority. Open education is foreseen as a way of innovating tertiary education and also a way of maximizing the potential benefit of existing resources, especially in regions where access to education may still be limited. But an important issue remains regarding the transferability of the OER model: to what extent is OER as a concept applicable, transferable and relevant in nonWestern contexts? (Richter \& McPherson, 2012).

In this paper, we have questioned how professors within the Middle East region go about reusing and localising OER that were prepared and developed within a Western context. Do educational resources developed within a studentled educational system work out in a teacher-centred education? While our experts spoke about different ways of localising content, other implicit aspects emerged. Open education is based on motivation. Similar to other sub-cultures, such as those characteristic of open source communities, it is based on enthusiasm of users and developers who are able to think outside the box, who are pioneers in shifting existing models towards more innovative approaches.

From our results, we have learnt that the push towards open education needs to be a global, trans-local or local to local (Knowles, 2017) effort in terms of developing awareness about the benefits of open education, change of policy, developing incentives for people to use open education, setting up of a good platform and provide ICT training where necessary.

A major challenge lies in changing the cultural perception that opening education does not equal the dissemination of free resources. Opening up one's material, using the appropriate licenses could bring back other types of benefits. Moreover, our findings echo previous results which suggest that fear, insecurity and discomfort by educational professionals is related to lower frequency of OER use (Andrade et al., 2011).

Hofstede (1986) contends that cross-cultural teaching gaps can be overcome by two important approaches: (1) teaching teachers how to teach; and (2) teaching the learner how to learn. In the context of OER, this advice could not be more appropriate. Teachers will only embrace open education if they are taught how to teach using open education in their teaching. It is also important that professors are supported to understand how to develop their own OER, the be aware of the 4Rs of OER (reuse, revise, remix and redistribute), learn about the types of open licenses available, and also have access to professional development opportunities focusing on how to manage cultural diversity when opening up their courses. On the other hand, students will only use OER and exploit its benefits for their learning, if they understand how to use OER and if they are aware about how OER could benefit them in terms of their learning trajectory. These findings are similar to those found by Lesko (2013) in a study 
in South Africa, where the main barriers for using open education were lack of: knowledge related open education practices, awareness of the different approaches to licensing learning contents, institutional support, infrastructural problems and locating relevant OER, amongst others.

As evidenced by the experts' interview data in this study, global efforts should be developed and designed in accordance with one's culture. While in Egypt, open education approaches may be a sustainable solution to deal with the massive scale for the universities, in Palestine, it may be envisaged more as a bridge to the outside world. In Jordan, universities are working hard to attract students to engage in their lectures, hence, they do not see open education as a replacement for face-to-face learning.

It has been highlighted within the study findings how open education could also be an instrument for internationalisation, with the aim of preparing students for intercultural diversity and for developing intercultural competencies. Moreover, open education practices have a potential to transform and change cultural barriers related to both power distance and collectivists culture. For instance, we have seen how OER could be a driver for shifting the perception about acceptance of adult learning, the acceptance of a student-led instruction, increase in Arabic educational online content, etc. But more importantly, the findings illustrate that open education is also questioning the validity of traditional passive learning cultures and systems of hierarchy and ranking, which exist across academic institutions worldwide. In this respect, open education in itself has developed into a new sub-culture which is transforming education, through bottom-up approaches which offer more opportunities for the levelling of power and instead the possibility of co-creation, collaboration, evaluation and distributed pedagogical models, amongst others.

As discussed by Hofstede (2001), understanding the teacher/student relationship is fundamental when studying cross-cultural learning. Similarly, intercultural experiences can contribute to academic development (Herbert, 2006), providing experiences that allow awareness of cultural diversity (Forsman, 2012), and enabling changes in teaching and learning(Roberts, Brown, \& Edwards, 2015), which can facilitate collaborative work (Alcorn, 2010). While this study aimed to provide some orientation on the current open education practices in a range of Middle Eastern universities, more research is required to provide further insight into the teacher/student relationship in the Middle East and how this hinders or drives the effort in opening education practices in this region. 


\section{Conclusion}

Open education is viewed here as a collaborative subculture that aims to reduce access barriers to high quality educational content and counteract social inequality in learning. Whilst this poses a challenge for higher education institutions throughout the world, due to the persistence of hierarchical bureaucracies (Mintzberg, 1989), this only deepens the traditional tension between academic culture, oriented to generate and share knowledge, and the power structure of educational institutions (Austin, 1990). As a counter model, the practice of adopting open education is based on academic awareness, digital fluency, co-creation, agile pedagogies, and appropriate support and staff /student incentives, including the design and implementation of comprehensive institutional policies.

With this qualitative research, we have found that the Middle East region is no exception to this general trend, both in terms of educational challenges and the difficulties of its implementation. The universities collaborating on OpenMed, are arguably the most international and open profile organisations in this geographical environment. However, the observations of the region's experts have allowed us to illustrate how in countries with (comparatively) greater distance of power and (comparatively) greater collectivism, educational innovation has to redouble its efforts to overcome difficulties. The academic profile and focus on reputation and rank, is a central factor in any process of educational change and innovation. In this context, international inter-university cooperation initiatives, such as OpenMed provide an all-important driver for initiatives that can facilitate cultural exchange in educational organisations for the betterment of society.

As in other geo-political scenarios, the universities of the Middle East have a central role in the articulation of local and international dimensions in their societies. In the case of the Middle East, this is reflected, among other aspects, in the dilemma between the development of open educational resources in English and / or Arabic. On the one hand, the English language contributes to internationalisation and makes it easier to reuse content (widely available in that language). On the other hand, the Arabic language improves the positioning of the region and depending on the subject being taught, favours the local relevance of the content. The socio-technological design of open education resources is a strategic factor in its potential for reuse and subsequent dissemination. This dilemma epitomizes how each university attempts to combine local cohesion with integration in international networks. 


\section{Bibliography:}

Abdallah, M. M. (2017). Towards improving content and instruction of the 'TESOL/TEFL for Special Needs' course: an action research study. Educational Action Research, 25(3), 420-437.

Abeywardena, I. S. (Producer). (2012). The Re-use and Adaptation of Open Educational Resources (OER): An Exploration of Technologies Available. Retrieved from https://oerknowledgecloud.org/sites/oerknowledgecloud. org/files/ExplorationOfTechnologiesAvailable_OER.pdf

Affouneh, S., Wimpenny, K., Ra'fat Ghodieh, A., Alsaud, L. A., \& Obaid, A. A. (2018). Reflection on MOOC Design in Palestine. International Review of Research in Open and Distributed Learning, 19(2).

Al-Harthi, A. S. (2005). Distance Higher Education Experiences of Arab Gulf Students in the United States: A cultural perspective. The International Review of Research in Open and Distributed Learning, 6(3).

Al-Qura'n, M., Haikal, A. A., Razeq, A. M., Shalabi, M., Fathi, N., Ghoush, A. S., \& Majdalawi, T. (2001). The development and implementation of a sixth grade geology unit through collabrative action research. Educational Action Research, 9(3), 395-411.

Alcorn, N. (2010). Knowledge through a Collaborative Network: A CrossCultural Partnership. Educational Action Research, 18(4), 453-466. doi:1 $0.1080 / 09650792.2010 .524783$

Anakwe, U. P., Kessler, E. H., \& Christensen, E. W. (1999). Distance learning and cultural diversity: Potential users' perspective The International Journal of Organizational Analysis, 7(3), 224-243. doi:doi:10.1108/ eb028901

Andrade, A., Ehlers, U., Caine, A., Carneiro, R., Conole, G., Kairamo, A., . . . Holmberg, K. (2011). Beyond OER: Shifting focus to open educational practice (OPAL Report 2011). Retrieved from https://oerknowledgecloud. org/sites/oerknowledgecloud.org/files/OPAL2011.pdf

Archers, M. S. (1979). Social origins of educational systems. Beverly Hills, CA: Sage.

Asgharzadeh, A. (2008). The Return of the Subaltern: International Education and Politics of Voice. Journal of Studies in International Education, 12(4), 334-363. doi:10.1177/1028315307308137

Auyeung, P., \& Sands, J. (1996). A cross cultural study of the learning style of accounting students. Accounting \& Finance, 36(2), 261-274. doi:10.1111/ j.1467-629X.1996.tb00310.x 
Bulger, M., Bright, J., \& Cobo, C. (2015). The real component of virtual learning: motivations for face-to-face MOOC meetings in developing and industrialised countries. Information, Communication \& Society, 18(10), 1200-1216. doi:10.1080/1369118X.2015.1061571

Butcher, N., \& Hoosen, S. (2014). Harnessing OER to drive Systematic Educational Change in Secondary Schooling. Journal of Learning for development, 3(1).

Cachia, R., \& Maya-Jariego, I. (2018). Opening education in the MENA region: In-depth interviews and Focus Group data with experts in open education in Egypt, Jordan, Lebanon, Morocco and Palestine. Retrieved from: http://doi.org/10.5281/zenodo. 1283114

Castaño-Muñoz, J., Kreijns, K., Kalz, M., \& Punie, Y. (2017). Does digital competence and occupational setting influence MOOC participation? Evidence from a cross-course survey. Journal of Computing in Higher Education, 29(1), 28-46.

Castaño Muñoz, J., Redecker, C., Vuorikari, R., \& Punie, Y. (2013). Open Education 2030: planning the future of adult learning in Europe. Open Learning: The Journal of Open, Distance and e-Learning, 28(3), 171-186. doi:10.1080/02680513.2013.871199

Dunn, R. (1983). Learning style and its relationship to exceptionality at both ends of the spectrum. Exceptional Children, 4(6), 496-506.

Ember, C. R., \& Ember, M. (2009). Cross-cultural research methods. Lanham: AltaMira Press.

Forsman, L. (2012). Investigating the cultural dimension in foreign language education - from transmission of facts to dialogical uptake. Educational Action Research, 20(4), 483-496. doi:10.1080/09650792.2012.727602

Garson, K. (2016). Reframing internationalization. The Canadian Journal of Higher Education, 46(2), 19-30.

Gervedink Nijhuis, C. J., Pieters, J. M., \& Vogt, J. M. (2013). Influence of Culture on Curriculum Development in Ghana: an undervalued factor? Journal of Curriculum Studies, 45(2), 225-250.

Hatakka, M. (2009). Build it and They Will Come? - Inhibiting Factors for Reuse of Open Content in Developing Countries. The Electronic Journal of Information Systems in Developing Countries, 37(1), 1-16. doi:10.1002/j.1681-4835.2009.tb00260.x

Heine, S. J. (2011). Cultural psychology. New York: WW Norton.

Herbert, S. (2006). The challenges of designing and implementing a crosscultural unit of work. Educational Action Research, 14(1), 45-64. doi:10.1080/09650790600585269 
Hofstede, G. (1980). Culture's consequences: International differences in work-related values. Beverly Hills, CA: Sage.

Hofstede, G. (1986). Cultural difference in teaching and learning. International Journal of Intercultural Relations, 10, 301-320.

Hofstede, G. (2001). Culture's consequences: Comparing values, behaviours, institutions, and organizations across nations. California: Sage Publications.

Hofstede, G. (2011). Dimensionalizing Cultures: The Hofstede Model in Context. Online Readings in Psychology and Culture, 2(1).

Hofstede, G., \& Bond, M. H. The Confucius connection: from cultural roots to economic growth. Organizational Dynamics, 16, 4-21.

Jones, M. (2007). Hofstede - Culturally Questionable? Paper presented at the 2007 Oxford Business and Economics Conference, Oxford, UK.

Knowles, R. V. (2017). A translocal approach to dialogue-based art. (PhD Thesis), Plymouth University.

Knox, J. (2014). Digital culture clash: "massive" education in the E-learning and Digital Cultures MOOC. Distance Education, 35(2), 164-177. doi:10 $.1080 / 01587919.2014 .917704$

Leeds, B. (2014). Temporal experiences of e-learning by distance learners. Education + Training, 56(2/3), 179-189. doi:doi:10.1108/ET-11-20120114

Lenartowics, T., \& Roth, K. (2001). Does Subculture within a Country Matter? A Cross-Culture Study of Motivational Domains and Business Performance in Brazil. Journal of International Business Studies, 32(2), 305-325.

Lesko, I. (2013). The use and production of OER \& OCW in teaching in South African higher education institutions (Case Study). Open Praxis, 5(2), 103-121. doi:http://dx.doi.org/10.5944/openpraxis.5.2.52

Marcus, A. (2000). International and intercultural user-interface design. In C. Stephanidis (Ed.), User interfaces for all. New York: Lawrence Erlbaum.

Maya Jariego, I. (2017). Localising Open Educational Resources and Massive Open Online Courses.

Maya Jariego, I., \& Santolaya, F. J. (2016). Comparison of cultural causal attributions in European and Arabic regions in the Mediterranean. Erasmus + OpenMed Program. Paper presented at the Open up education in South-Mediterranean countries. UNIMED, Mediterranean Universities Union, May 3-4, 2016., Coventry, United Kindgdom.

Minkov, M., \& Hofstede, G. (2012). Hofstede's Fifth Dimension: New Evidence From the World Values Survey. Journal of Cross-Cultural Psychology, 43(1), 3-14. 
Nasif, E. G., Al-Daeaj, H., Ebrahimi, B., \& Thibodeaux, M. S. (1991). Methodological Problems in Cross-Cultural Research: An Updated Review. MIR: Management International Review, 31(1), 79-91.

Nelson, K. G., \& Clark, T. D. (1994). Cross-cultural issues in information systems research: A research program. Journal of Global Information Management, 2(4), 19-29.

OECD (Producer). (2012). Education at a Glance 2012. Retrieved from http:// www.oecd-ilibrary.org/docserver/download/9612031e.pdf?expires $=1520$ $\underline{\text { 588106\&id }=\mathrm{id} \& \text { accname }=\text { guest } \& \text { checksum }=\text { EB2A41FD7A674049CE0 }}$ B963FA5688CA1

Ramburuth, P., \& McCormick, J. (2001). Learning diversity in higher education: A comparative study of Asian international and Australian students. Higher Education, 42(3), 333-350. doi:10.1023/a:1017982716482

Richter, T., \& McPherson, M. (2012). Open educational resources: education for the world? Distance Education, 33(2), 201-219. doi:10.1080/015879 19.2012.692068

Roberts, D. M., Brown, A. M. B., \& Edwards, L. (2015). Participatory Action Research in Two Primary Schools in a Rural Tanzanian Village: An Exploration of Factors to Cultivate Changes in Teaching and Learning. Educational Action Research, 23(3), 366-382. doi:10.1080/09650792.20 15.1009925

Schkade, L. L., Romani, S., \& Uzawa, M. (1978). Human information processing and environmental complexity: An experiment in four cultures. Journal of Management, 8, 56-63.

Schribner, S., \& Cole, M. (1981). The psychology of literacy. Cambridge, MA.: Harvard University Press.

Signorini, P., Wiesemes, R., \& Murphy, R. (2009). Developing alternative frameworks for exploring intercultural learning: a critique of Hofstede's cultural difference model. Teaching in Higher Education, 14(3), 253-264. doi:10.1080/13562510902898825

Søndergaard, M. (1994). Research Note: Hofstede's Consequences: A Study of Reviews, Citations and Replications. Organization Studies, 15(3), 447456. doi:10.1177/017084069401500307

Sugahara, S., \& Boland, G. (2010). The Role of Cultural Factors in the Learning Style Preferences of Accounting Students: A Comparative Study between Japan and Australia. Accounting Education, 19(3), 235-255. doi:10.1080/09639280903208518

Tang, K. C. C. (1993). Spontaneous Collaborative Learning: A New Dimension in Student Learning Experience? Higher Education Research \& Development, 12(2), 115-130. doi:10.1080/0729436930120201 
Thomas, A. (2008). Focus groups in qualitative research: culturally sensitive methodology for the Arabian Gulf. International Journal of Research \& Method in Education \& Training, 31(1), 77-88. doi:10.1080/17437270801919941

UNESCO. (2012). The 2012 Paris OER Declaration. Retrieved from http:// www.unesco.org/new/fileadmin/MULTIMEDIA/HQ/CI/WPFD2009/ English Declaration.html

Venter, K. (2003). Coping with Isolation: the role of culture in adult distance learners' use of surrogates. Open Learning: The Journal of Open, Distance and e-Learning, 18(3), 271-287. doi:10.1080/0268051032000131035

Villar-Onrubia, D., \& Rajpal, B. (2016). Online international learning. Perspectives: Policy and Practice in Higher Education, 20(2-3), 75-82. doi:10.1080/13603108.2015.1067652

Yemini, M., \& Sagie, N. (2016). Research on internationalisation in higher education - exploratory analysis. Perspectives: Policy and Practice in Higher Education, 20(2-3), 90-98. doi:10.1080/13603108.2015.1062057

Zualkernan, I. A., Allert, J., \& Qadah, G. Z. (2006). Learning Styles of Computer Programming Students: A Middle Eastern and American Comparison. IEEE Transactions on Education, 49(4), 443-450. doi:10.1109/TE.2006.882366 